Snails, and more crabs and swarming shrimps arrived $^{1}$. It was a never-before-told story of biological succession. But it was unclear whether the organisms taking over the vents were from local sources or came from far away. Nor was it clear whether species composition in the region had changed as a result of the eruption, says Shank, because the area had not been studied in great detail previously.

This is where Mullineaux, a specialist in marine larvae, comes in. Although many vent inhabitants are fused to the sea floor or to other organisms as adults, most spend their early lives as free-swimming larvae that can ride the currents to new homes. She and her team have been studying larvae at Nine North ever since the 1991 eruption. They've collected them at different depths and at the sea floor to get a sense of abundance and species make-up.

As Mullineaux and her colleagues describe in a paper published this year ${ }^{2}$, the species composition of the larvae at the hydrothermal vents changed markedly after the 2006 eruption. Larvae from species common at the site before the eruption were nowhere to be seen afterwards - even though there were potential sources of recolonization within a few kilometres. By contrast, other species that had been rare became abundant after the catastrophe.

The Woods Hole team also discovered larvae of a species never seen before at Nine North, a rock-clinging snail called Ctenopelta porifera. The nearest hydrothermal system known to host the species is more than 300 kilometres to the north. "This has greatly exceeded our expectation of how far vent larvae could travel in the ocean," says Mullineaux.

Mullineaux's group had in 2001 calculated that a larva with a lifespan of about a month could travel at most up to 100 kilometres from Nine North and that the majority stayed within 60 kilometres $^{3}$. Even if larvae lived longer, they wouldn't be able to travel farther; the flow of the current reverses every few weeks along the ridge axis and so limits how far larvae could go. How C. porifera had made a 300-kilometre journey was a mystery.

\section{Complex flow}

The researchers had based their calculation of flow on measurements of the current at a single location at the crest of the ridge, and assumed that the direction and speed of the currents were the same over the whole area. "This is a reasonable assumption in many parts of the ocean," says Andreas Thurnherr, a physical oceanographer at Columbia University's Lamont-Doherty Earth Observatory in Palisades, New York. But the topography of Nine North disrupts current flow significantly, he says.

To better estimate currents, Thurnherr, Mullineaux and their colleagues placed 15 current-measuring devices along the crest and both flanks of the ridge; they also deployed two mobile current meters that travelled between the sea floor and the top of the ridge, sampling as they went. The team found that currents near the crest of the ridge were faster than those farther away, and that currents on the eastern flank of the ridge flowed southwards, whereas those on the west side went northwards.

Surprisingly, the study shows that currents closer to the sea floor are among the strongest, at about 10 centimetres per second ${ }^{4}$. This caught the researchers by surprise. "Our observations are markedly different from the much weaker and wider currents we see in many areas of the deep ocean," says Thurnherr. It may also explain how $C$. porifera larvae could travel so far.

Diane Adams, a former graduate student of Mullineaux's, uncovered another surprise. She had noted a drop in larval abundance at Nine North whenever surface eddies - loops of rotating currents resulting from differences in water density interacting with Earth's rotation - were passing by above.

The researchers hadn't thought that surface eddies could reach down to the ocean floor, but they were able to pick up signals of rotating current loops a short time after surface eddies passed by. "The surface eddies could, in effect, blast larvae off the ridge and have an important role in their dispersal," says Mullineaux.

Such interplay between geology and ocean currents has fascinated researchers of chemosynthetic life for decades. "It's important not only for recolonization after natural disasters

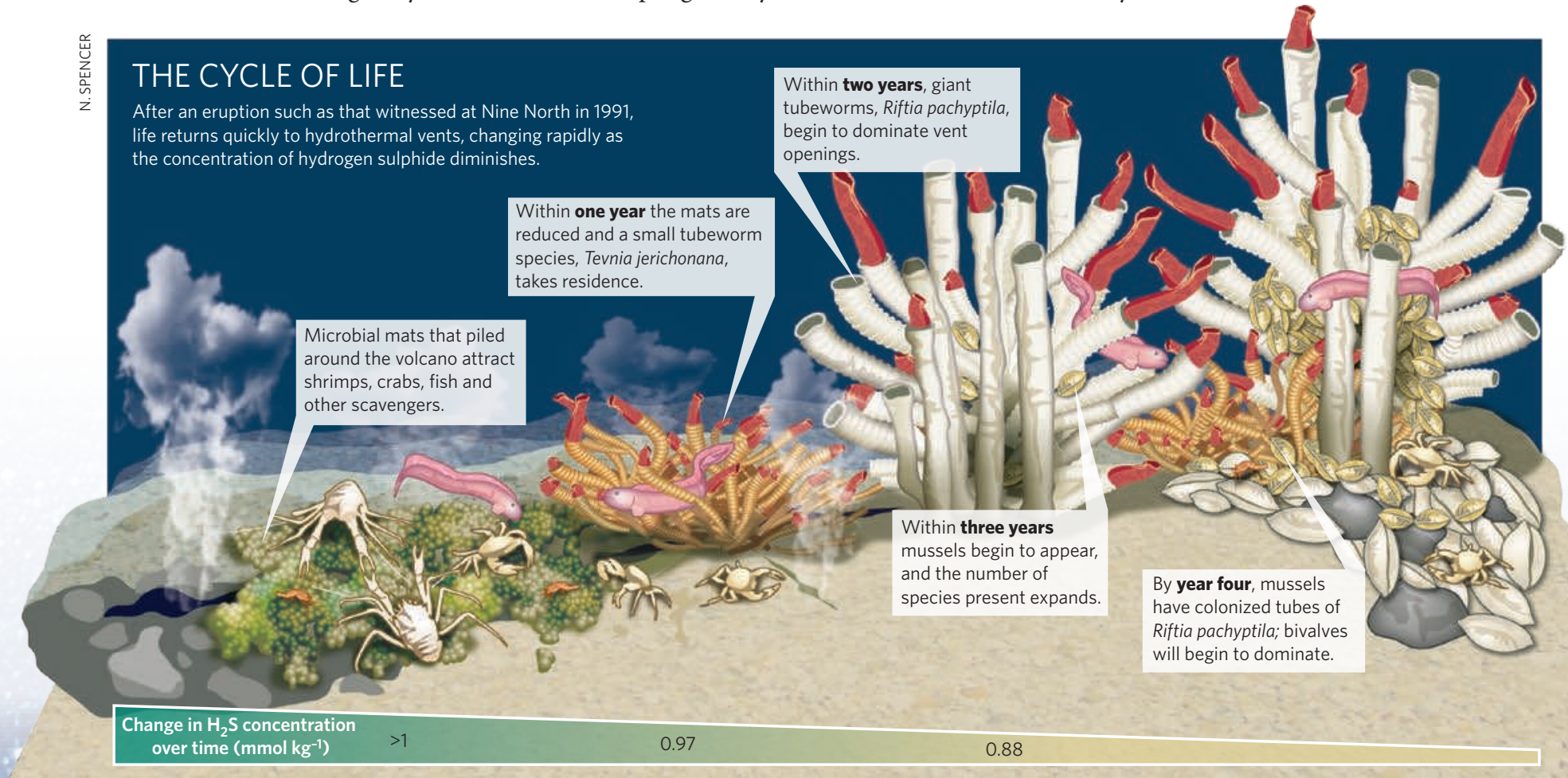




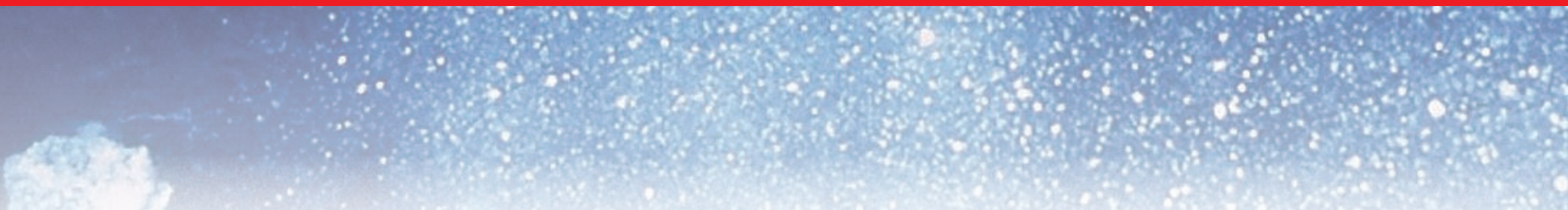

but for the evolutionary connectivity of marine life," says Robert Cowen, a marine biologist at the University of Miami in Florida.

Researchers want to know why pockets of life-enabling chemicals in different parts of the ocean host distinct yet overlapping assemblages of species. And where did these species originate? Did they arise first at the vents or perhaps in shallow-water cold seeps - areas where hydrogen sulphide and hydrocarbon sources such as methane leak out from Earth's interior? And how do organisms such as those living off the sulphide-laden oozes of dead whales contribute to the connectivity between chemosynthetic communities?

The key to the divergence and convergence of these marine species during evolution lies in the ability of larvae to negotiate ocean currents, geological barriers and changes in sea-floor topology over millions of years. In this amount of time, the movement of only a small number of larvae is sufficient to allow genetic exchange between geographically separated populations. The scale of such connectivity "can be astonishing", says Charles Fisher, a marine biologist at Pennsylvania State University in University Park.

\section{Long-distance taxi}

Fisher's team has found, for example, that some species of tubeworm and mussel living on cold seeps in the Gulf of Mexico are genetically related to their counterparts off the west coast of Nigeria, an indication of genetic exchange between two regions that are more than 10,000 kilometres apart ${ }^{5}$. This connectivity occurs over numerous generations through steps that are not yet clear. But researchers suspect it may be aided by the equatorial deep jets in the Atlantic, which alternate between easterly and westerly flow depending on depth and so could transport larvae both ways.

In other instances, larval dispersal is blocked over quite short distances, leading to speciation. In the northeastern Pacific Ocean, the 450-kilometre-long Blanco transform fault has separated the Juan de Fuca and Gorda ridge systems, off the coast of Washington State and Oregon (see 'Curiosities of the deep'). Vrijenhoek's team has found that similar-looking snails at Juan de Fuca and Gorda are related, but quite different, species that diverged roughly 11 million years ago, consistent with the time of the fault's formation ${ }^{6}$.

But, says Vrijenhoek, “the barrier doesn't affect all animals in the same way". The tubeworms at the two ends of the fault, for example, are the same species, even though there are some slight genetic differences ${ }^{7}$. Gene flow has taken place from populations in the north to their southern counterparts, the same direction as the ocean currents in the region. "Tubeworm larvae probably have a sufficiently long lifespan or stay at the right parts of the water column to allow them to make that jump," he says.

Geological changes may have separated species in other locations as well. For example, the Logatchev hydrothermal vent, located just east of the Caribbean, is the only place in the Mid-Atlantic Ridge known to host vesicomyid clams, which are more typical of the Pacific. Some researchers suspect that the animals biodiversity of the ocean. "Some strategic locations are missing pieces of the puzzle of how things have evolved." These include the Arctic and the Antarctic, where thick ice and turbulent seas make exploration immensely challenging.

Others include the Chile triple junction, where three tectonic plates meet, resulting in the subduction of the Chile rise, a mid-ocean ridge, under the South American plate. "There you have the potential for vents and seeps in close proximity," says Tyler. "This allows you to address the evolutionary relationship between vent and seep animals without the variable of geography."

\section{CURIOSITIES OF THE DEEP}

Researchers have focused on several hydrothermal-vent communities around the world for the lessons they can teach in biogeography.

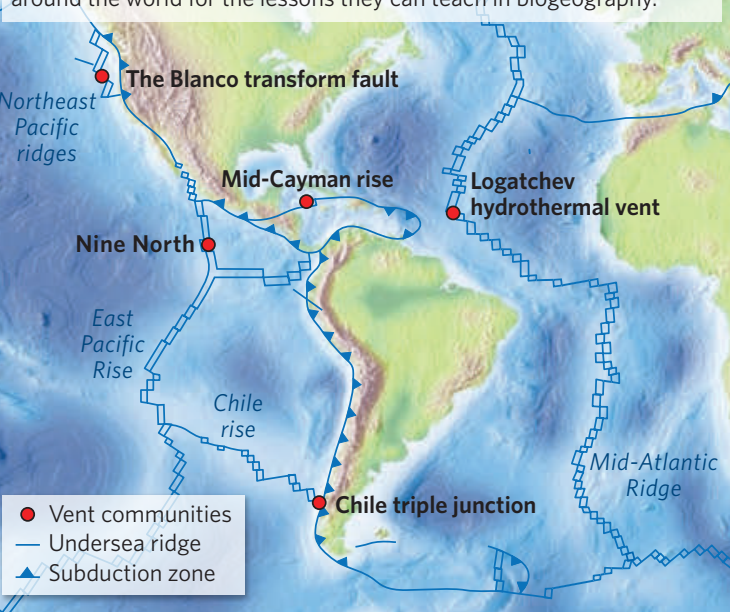

\section{The great unknown}

To many, the Caribbean, especially the little-explored Mid-Cayman rise near the island of Grand Cayman, might hold the key to some of the most perplexing questions in deep-sea biology. At almost 5,000 metres deep, hydrothermal vents in the region should exist at unrecorded environmental extremes and may reveal new species. The location is also ideal for studying the role of the isthmus of Panama in the divergence and connectivity of vent species.

Researchers wonder whether the fauna on the Mid-Cayman rise will be more closely related to that on the East Pacific Rise, on the other side of the Panama land bridge, or to the organisms on the Mid-Atlantic Ridge. Chris German, a marine geochemist at WHOI

might have originated from the Pacific arriving through an ancient seaway between North and South America before the rise of the isthmus of Panama 5 million years ago.

Other marine biologists, including Cindy Van Dover, a deep-sea biologist at Duke University Marine Laboratory in Beaufort, North Carolina, say that the clam species are probably more common on the Mid-Atlantic Ridge than it looks at present and didn't necessarily originate in the Pacific. "We simply don't have enough samples to know for sure." This highlights a limitation for this relatively young research field: scientists have only a rudimentary knowledge of the distribution of chemosynthetic life, let alone the underlying mechanisms of connectivity and speciation ${ }^{8}$.

So far, only 200 or so hydrothermal vents and a few dozen cold seeps have been discovered around the world. "Most parts of the ocean are unexplored," says Paul Tyler, a marine biologist at the National Oceanography Centre in Southampton, UK, and chair of the Biogeography of Deep-Water Chemosynthetic Ecosystems (ChEss) programme of the Census of Marine Life, a global initiative to document the and co-chair of the ChEss programme, led an expedition in October 2009 that detected signals of hydrothermal plumes near the MidCayman rise. A follow-up expedition by the UK National Oceanography Centre managed to find the vents at a depth of 5,000 metres, the deepest ever recorded. As to what they found there, the team would say little. Nevertheless, German warns to keep expecting surprises. "A few years ago, we thought we knew everything about geological barriers and ocean currents to predict what we are going to find, but we have been wrong every time since."

Jane Qiu writes for Nature from Beijing, China.

1. Shank, T. M. et al. Deep Sea Res. /l 45, 465-515 (1998).

2. Mullineaux, L. S., Adams, D. K., Mills, S. W. \& Beaulieu, S. E. Proc. Natl Acad. Sci. USA 107, 7829-7834 (2010).

3. Marsh, A. G., Mullineaux, L. S., Young, C. M. \& Manahan, D. T. Nature 411, 77-80 (2001).

4. McGillicuddy, D. J., Lavelle, J. W., Thurnherr, A. M Kosnyrev, V. K. \& Mullineaux, L. S. Deep-Sea Res. I (in the press).

5. Cordes, E. E. et al. Deep Sea Res. / 54, 637-653 (2007)

6. Johnson, S. B., Young, C. R., Jones, W. J., Waren, A. \& Vrijenhoek, R. C. Biol. Bull. 210, 140-157 (2006).

7. Young, C. R., Fujio, S. \& Vrijenhoek, R. C. Mol. Ecol. 17, 1718-1731 (2008)

8. Van Dover, C., German, C. R., Speer, K. G., Parson, L. P. \& Vrijenhoek, R. C. Science 295, 1253-1257 (2002). 